УДК 621.914 .1

DOI: https://doi.org/10.26642/ten-2020-2(86)-54-60

В.М. Рубан, ст. викладач

Національна металургійна академія Украӥни

\title{
Моделювання процесу механічної обробки профілю робочої поверхні колісних пар на верстатах КЖ20
}

\author{
(Представлено: д.т.н., професор Сладковські Олександр)
}

У машинобудуванні існує клас деталей з кусково-лінійною або з криволінійною робочою поверхнею, до таких деталей належать колісні пари машин рейкового транспорту. Під час експлуатації локомотивів магістрального і промислового залізничного транспорту періодично з'являється необхідність відновлення зношеного профілю коліс без демонтажу колісних пар. У статті проведено аналіз та зауважено про необхідність вдосконалення процесу технологіi відновлювального ремонту колісних пар локомотивів. Від якості й точності процесу відновлювального ремонту залежить ефективність і надійність роботи спеціальних фасонних фрез і машин рейкового транспорту. Описано методику дослідження динаміки процесів різання на спеціальних верстатах КЖ20, під час якої необхідно враховувати не тільки сили різання, але й структурні властивості фасонних фрез (інструменту), так і оброблюваної деталі (робочоі поверхні колісних пар). Вказано результати побудови імітаційної математичної моделі процесу відновлення робочого профілю бандажів на колесофрезерних верстатах КЖ20, за допомогою якої можна визначати зони стійких параметрів динаміки процесу фрезерування, в умовах одночасної наявності двох нежорстких елементів (оброблюваної деталі і спеціальної фасонноі фрези). Запропоновано метод визначення величини обертального моменту з урахуванням передаточного відношення механічної передачі.

Ключові слова: відновлення робочих поверхонь; колісні пари; колесофрезерний верстат КЖ20; моделювання процесу фрезерування; обертальний момент.

Актуальність теми. У сучасному виробництві проєктування технологічних процесів здійснюється за допомогою розв'язання задач оптимізації. Найбільш гнучкими, застосовними для оптимізаційних задач, $є$ імітаційні моделі, які відтворюють процес механічної обробки, дозволяючи відстежувати його розвиток у часі.

Аналіз останніх досліджень та публікації, на які спирається автор. Відновлення профілю робочих поверхонь коліс [1-3] і бандажів [4, 5] колісних пар машин рейкового транспорту, які мають поверхневі дефекти накопленого термомеханічного напруження, проводять у локомотивних депо [6]. Для зниження вартості ріжучого інструменту необхідно підвищити його стійкість і коефіцієнт використання, так за умови переривистого різання виникає удар, який випробують контактні поверхні інструменту під час врізання у заготовку, циклічне охолодження, це негативно впливає на зносостійкість інструменту і якість профілю обробленої поверхні [7]. Для відновлення профілю робочої поверхні колісних пар без їх викочування, застосовують колесофрезерні верстати КЖ20. Оскільки колісні пари зазвичай мають повзуни, рекомендується обробляти їх за постійної швидкості різання 60-80 м/хв, навіть у тих випадках, коли повзунів немає. Застосування цієї швидкості різання оберігає фасонні фрези від надмірного зносу і відколів твердосплавних циліндричних різальних елементів. Швидкість різання 60-80 м/хв досягається установкою змінних шестерень, які забезпечують 93-120 обертів шпинделя за хвилину. Величина хвилинної подачі вибирається у межах 100-150 мм/хв [8].

Менше значення подач на 25-30 \% варто застосовувати під час обробки колісних пар маневрових тепловозів і в тих випадках, коли глибина різання перевищує 5 мм. Перед початком обробки необхідно перевірити відповідність табличноїі фактичної кругової подачі. Врізання фрез необхідно проводити короткими імпульсами. За умови величини прокату колісної пари до 4 мм врізання необхідно проводити на довжині 300 мм, понад 4 мм на довжині 400 мм. За малої довжини врізання може відбуватися ковзання провідних роликів. Під час відновлення робочих поверхонь колісних пар 3 дефектом накопиченого термомеханічного напруження відбуваються значні стрибки сили різання, які еквівалентні ударам по передній поверхні циліндричних різальних елементів [9].

Залежність напруження, що виникає на передній поверхні різального елемента у момент ударної взаємодії з дефектом від напруження під час стабільного різання [9]:

$$
\sigma_{y \partial}=\sigma_{c m} \cdot \mu
$$

де $\sigma_{y \partial}$ - напруження, що виникає під час удару, МПа;

$\sigma_{c m}$ - напруження під час стабільного різання, МПа;

$\mu$ - коефіцієнт, який залежить від моменту інерції технологічної системи і швидкості різання. 
У [10] пропонується використовувати два критерії стійкості: основний, який оцінює амплітуди вібрацій фрези, і додатковий, що оцінює якість оброблювальної поверхні. Результати роботи зводяться до визначення зон стійких параметрів режимів різання, за яких можливе отримання підвищення якості обробленої поверхні.

Метою статті $є$ побудова математичної моделі процесу механічної обробки профілю робочої поверхні колісних пар на верстатах КЖ20, в умовах одночасної наявності двох нежорстких елементів (оброблюваної деталі і спеціальної фасонної фрези), для дослідження можливостей підвищення ефективності використання спеціальних фасонних фрез.

Викладення основного матеріалу. Величина сили різання нелінійно зростає від нуля у момент торкання різального елемента фрези робочої поверхні колісної пари до максимуму в момент виходу різального елемента фрези 3 контакту із робочою поверхнею колісної пари. Сила різання на $i$-му різальному елементі фрези в будь-який момент часу визначається товщиною шару матеріалу, що зрізається $i$-м різальним елементом фрези. Товщину зрізаного шару запропоновано визначати як суму номінальної товщини зрізаного шару, яка залежить від величини подачі на зуб і поточного кута повороту зуба фрези, і динамічної похибки, викликаної пружними деформаціями елементів технологічної системи.

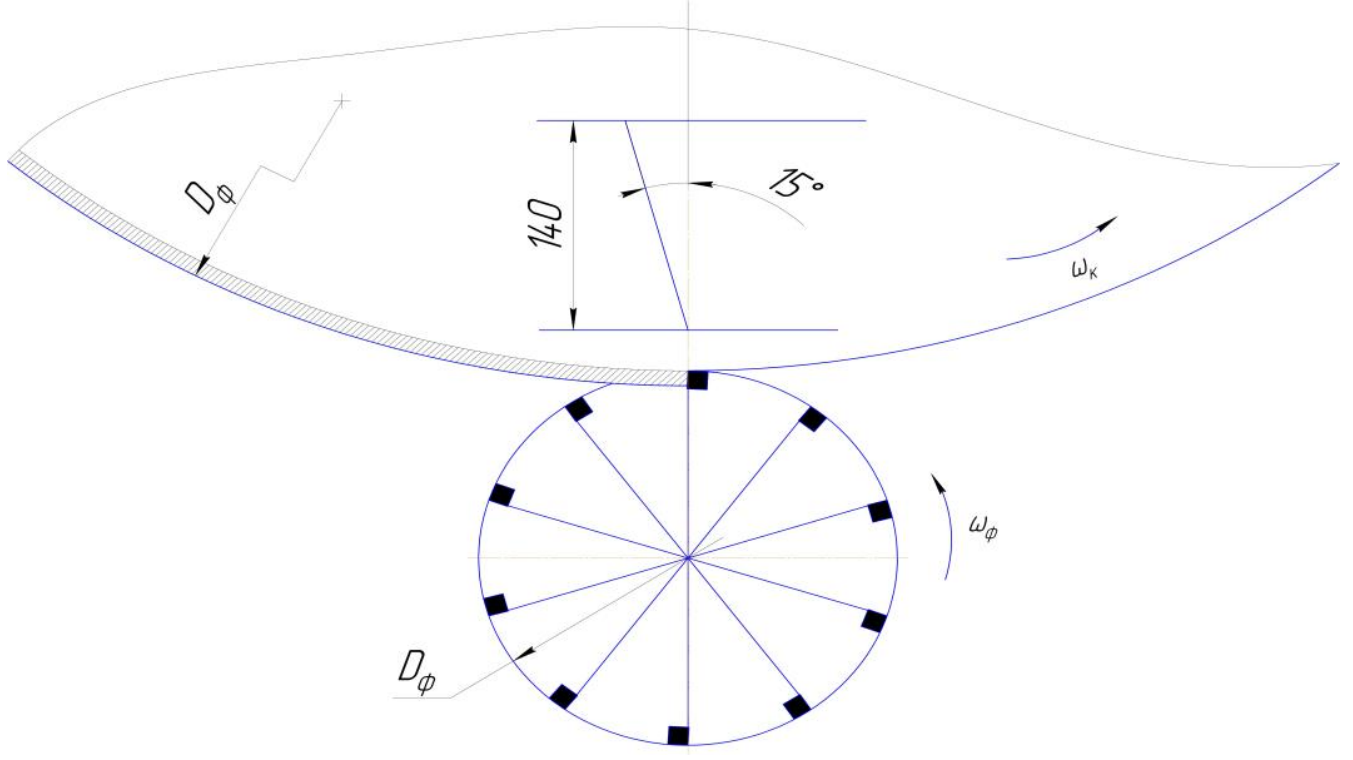

Рис. 1. Схема процесу фрезерування колеса

Товщину шару, що зрізається $i$-м різальним елементом фрези в момент часу $t$ можна визначити як:

$$
a_{i}(t)=\left\{\begin{array}{l}
S_{z} \sin \omega_{\phi} t+(x(t)-x(t-T)) \cos \omega_{\phi} t+\left(y(t-T) \sin \omega_{\phi} t\right) \\
n p u \quad 2 \pi n_{k}+(i-1) \frac{2 \pi}{z} \leq \omega_{\phi} t \leq 2 \pi n_{k}+(i-1) \frac{2 \pi}{z}+\varphi_{0} \\
0 \text { при } 2 \pi n_{k}+(i-1) \frac{2 \pi}{z}-\varphi_{0}<\omega_{\phi} t<2 \pi\left(n_{k}+1\right)+(i-1) \frac{2 \pi}{z}
\end{array},\right.
$$

де $n_{k}$ - число обертів фрези з початку різання;

$T$ - час повороту фрези на один різцетримач;

$\varphi_{0}$ - кут контакту фрези з поверхнею обробки;

$z$ - кількість різцетримачів фрези;

$S_{z}$ - подача на різцетримач фрези;

$x(t), x(t-T), y(t-T)$ - переміщення інструменту у момент часу $t$ i $t-T$ відповідно;

$\omega_{\phi}-$ кутова частота фрези.

У [11] наводиться методика визначення сили різання для різального елемента спеціальною фасонною фрезою до верстата КЖ20 [12]. Площа поперечного перерізу для фасонної фрези зі 130 різцями становить $f_{130}=0,88$ мм $^{2}$ і сила різання $-P_{z} 130=2030 \mathrm{H}$, а для фасонної фрези зі 182 різцями площа поперечного перерізу становить $f_{182}=0,62$ мм² $^{2}$ (рис. 2, б) і сила різання $-P_{z} 182=1430 \mathrm{H}$. 
Для визначення періоду частоти різцетримачів використаємо формулу [13], підставивши замість кількості різцетримачів фрези кількість циліндричних різальних елементів і визначимо період їх частоти.

Для фрези зі 130 різальними елементами $\tau_{1}=0,00659$ хв, а для фрези зі 182 різальними елементами $\tau_{2}=0,0047$ хв, на рисунку 2 показана залежність дії сили різання від часу.

$$
\tau=\frac{60}{\Omega \cdot n_{\sum \text { різ.ел. }},}
$$

де $\Omega$ - частота обертання шпинделя, об/хв;

$n_{\sum \text { різ.ел. }}$ - кількість циліндричних різців фрези.

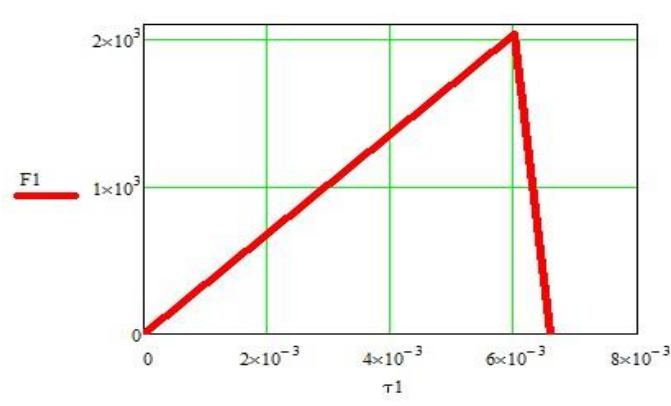

a)

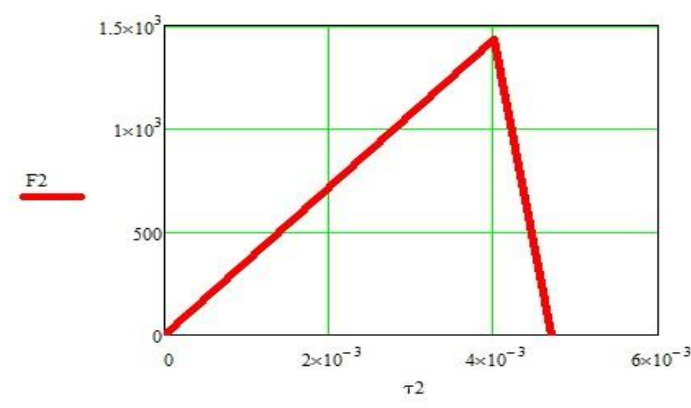

б)

Рис. 2. Залежність сили різання від часу:

а) для фрези зі 130 різальними елементами; б) для фрези зі 182 різальними елементами

Збільшення різальних елементів є логічним, це підтверджується графіками з рисунка 2. При цьому зменшується площа поперечного перерізу, сила різання, збільшується термін служби різальних елементів.

Математична модель процесу фрезерування. У процесі різання фреза робить відносний формоутворюючий рух, складений з обертального руху фрез і обертального руху колісної пари.

Фізична модель процесу фрезерування із двома ступенями свободи наведена на рисунку 3.

Вираження коливань технологічної системи [13-15] може бути описана виразом:

$$
\ddot{y}(t)+\varsigma_{y}^{2}(t)+\omega_{y}^{2} y(t)=F_{y}(t),
$$

де $\varsigma_{y}^{2}(t)=\frac{c}{m}-$ коефіцієнт демпфування;

$\omega^{2}=\frac{j}{m}-$ власна частота;

m - маса деталі;

$F_{y}(t)=A_{p} \sum_{j=1}^{z}\left[\left(K_{R} \cos \varphi_{j}-K_{T} \sin \varphi_{j}\right) h_{j}(t)\right]-$ сила різання;

$A_{p}$ - осьова глибина різання, мм;

$K_{R}-$ питомий коефіцієнт різання в радіальному напрямку;

$K_{T}-$ питомий коефіцієнт різання в тангенціальному напрямку

$h_{j}(t)=\left\{\begin{array}{c}f_{z} \sin \varphi_{j}+[x(t)-x(t-\tau(t))] \cos \varphi_{j} \text { if } \varphi_{s t}<\varphi_{j}<\varphi_{e x}-\text { товщина зрізу; } \\ 0 \text { otherwise }\end{array}\right.$

$f_{z}=\pi \cdot D_{k} \cdot \frac{n_{k}}{n_{f} \cdot z}-$ подача на різцетримач;

$D_{k}$ - діаметр колеса по колу кочення;

$n_{k}$ - частота обертання колеса;

$n_{f}$ - частота обертання фрези;

$\mathrm{z}$ - число різцетримачів фрези;

$x(t)$ - поточний стан інструменту; 
$x(t-\tau(t))$ - попереднє положення інструменту, регенеративна затримка $\tau(\mathrm{t}) \epsilon$ періодичною в часі в зв'язку зі зміною швидкості обертання шпинделя;

$\varphi_{s t}-$ кут входу інструменту;

$\varphi_{e x}-$ кут виходу інструменту.

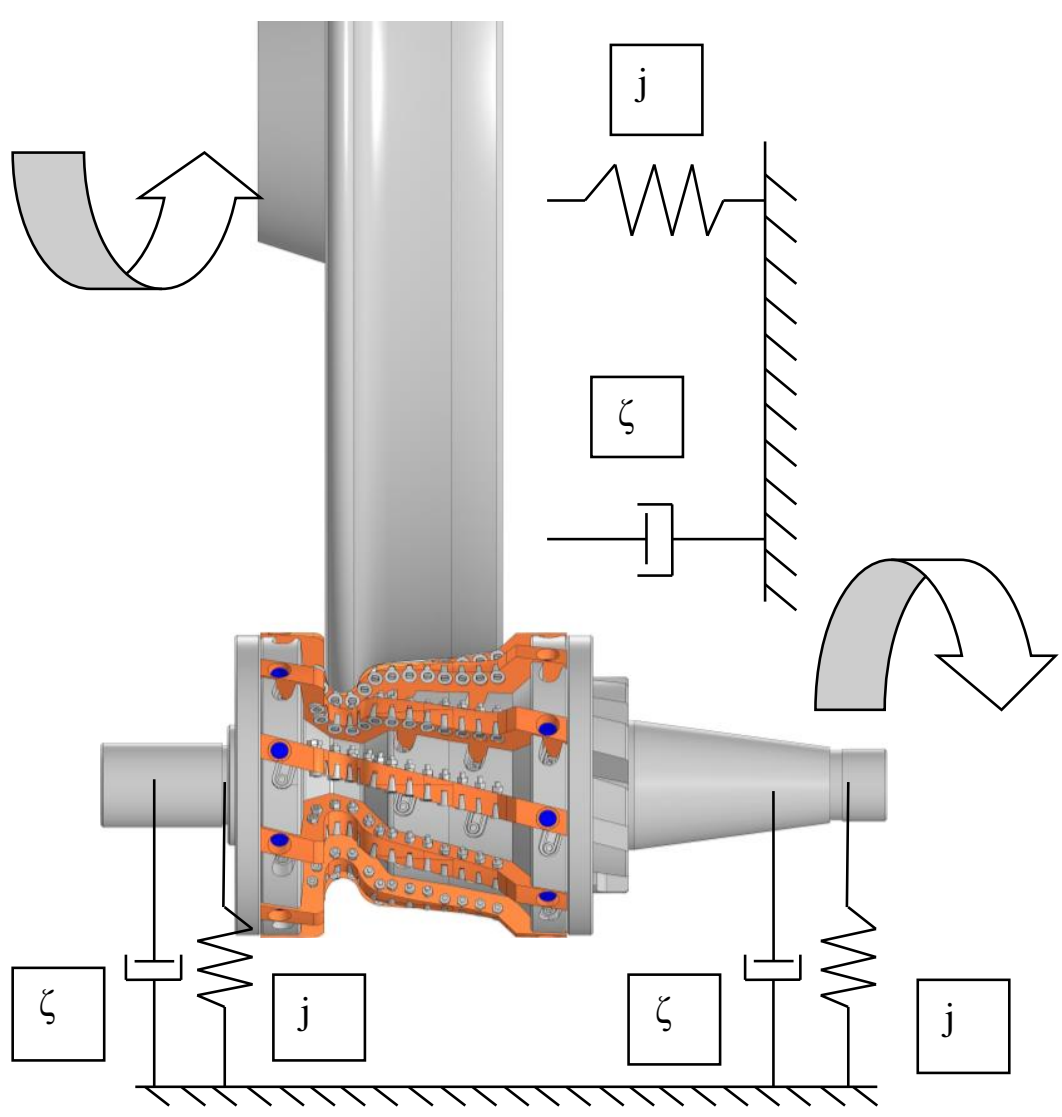

Рис. 3. Фізична модель процесу фрезерування із двома ступенями свободи

Розрахунковою схемою для опису динаміки процесу вважаємо одномасову коливальну систему із двома ступенями свободи.

Для визначення обертального моменту використовувався амперметр, включений у ланцюг двигуна приводу фасонними фрезами, встановлений на панелі керування верстатом.

Діаметри коліс по колу кочення становили ø 1250, 1050, 957 мм, твердість НВ 270. Дослідження проводилися з глибиною різання 1-6 мм, подачами 0,05-0,3 мм/зуб, швидкість різання по колу кочення $25-125 \mathrm{M} / \mathrm{xB}$

Експериментальні дані

Таблиияя 1

\begin{tabular}{|c|c|c|c|c|c|c|}
\hline \multirow{2}{*}{$\begin{array}{c}\text { o. } \\
\text { 3/пи }\end{array}$} & $\begin{array}{c}\text { Глиина t, } \\
\text { мм }\end{array}$ & \multirow{2}{*}{ Подача Sz, мм/ніж } & \multirow{2}{*}{$\begin{array}{c}\text { Швидкість V, } \\
\mathbf{M} / \mathbf{x B}\end{array}$} & \multicolumn{3}{|c|}{ Струм I, А } \\
\hline 1 & 1 & 0,3 & 105 & 10 & 7 & 6 \\
\hline 2 & 2 & 0,25 & 86 & 13 & 12 & 11 \\
\hline 3 & 3 & 0,2 & 79 & 20 & 19 & 18 \\
\hline 4 & 4 & 0,15 & 66 & 28 & 27 & 26 \\
\hline 5 & 5 & 0,1 & 53 & 39 & 39 & 35 \\
\hline 6 & 6 & 0,063 & 26,5 & 51,5 & 45 & 40 \\
\hline
\end{tabular}

Величину обертального моменту асинхронного двигуна можна отримати з виразу [16], з урахуванням передаточного відношення $i$ механічної передачі [17], вираз матиме вигляд: 


$$
M=\frac{p \cdot m_{1} \cdot R_{2}^{\prime} \cdot I_{2}^{\prime 2}}{\omega_{1} \cdot s} \cdot i,
$$

де $p$ - число пар полюсів $p=2$;

$m_{1}$ - число фаз обмотки $m_{1}=3$;

$R_{2}^{\prime}=\frac{E_{p . n .}}{1,73 \cdot I_{p . n .}}-$ резистивний елемент, Ом,

де $I_{p . n .}-$ номінальний струм ротора, А;

$E_{p . n .}-$ ЕРС між кільцями нерухомого розімкнутого ротора, В;

$I_{2}^{2}$ - величина приведеного струму ротора, А;

$s=\frac{n_{1}-n}{n_{1}}-$ різниця між швидкостями обертання магнітного поля і ротора;

де $n_{1}=\frac{60 f}{p}-$ швидкості обертання магнітного поля;

$\omega_{1}$ - частота живильної мережі, 50 Гц;

$i$ - передаточне відношення механічної передачі $i=\frac{n_{\partial}}{n_{\phi}}$.

Врізання робиться поступово, невеликими імпульсами на довжині 400 мм через радіус кола робочої поверхні колеса.

Графічно процес відновлення можна зобразити графічно, який наведено на рисунку 4, що складається із врізання, встановленого режиму і завершення обробки - вихід інструмента із зони різання.

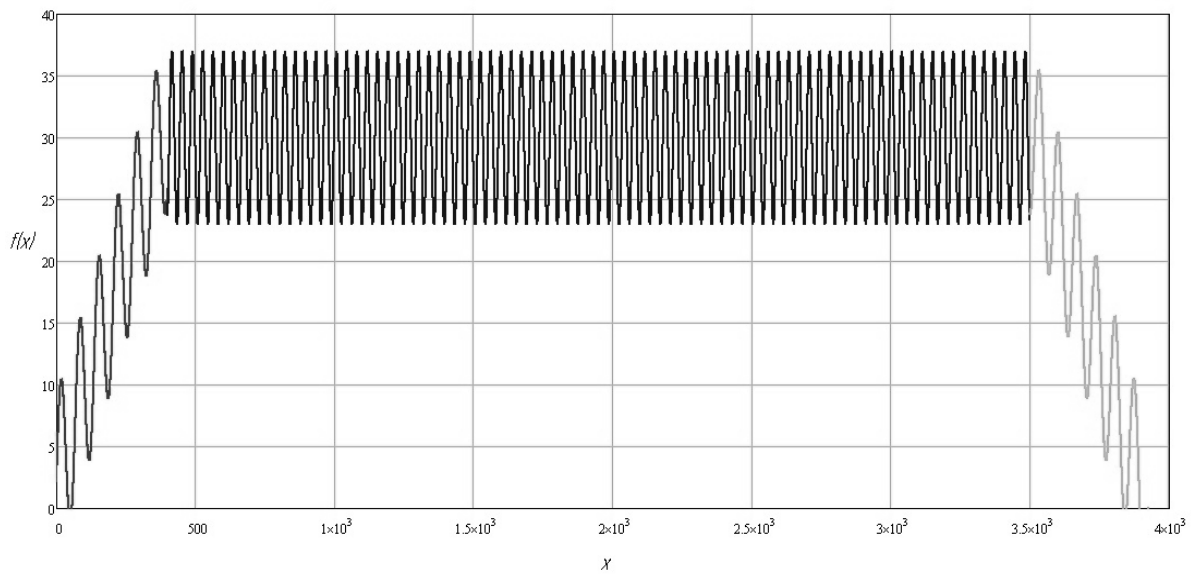

Рис. 4. Етапи обробки профілю робочої поверхні колеса

Визначення моменту процесу відновлення можна виразити системою рівнянь:

$$
M(\mathrm{x})=\left\{\begin{array}{l}
V_{M} \cdot x+M_{\max } \sin (\mathrm{x} \cdot \omega) \text { якщо } 0 \leq \mathrm{x} \leq 400 \\
M_{\max } \cdot \sin (x \cdot \omega)+M_{c p} \text { якщо } 400 \leq \mathrm{x} \leq 3600 \\
-V_{M} \cdot x+M_{\max } \cdot \sin (\mathrm{z} \cdot \omega)+M_{c p} \text { якщо } 3600 \leq \mathrm{x} \leq 4000
\end{array},\right.
$$

де $V_{M}$ - швидкість зростання моменту;

$M_{\max }$ - амплітуда коливань моменту;

$\omega$ - частота коливань моменту;

$M_{c p}$ - середній момент;

$x$ - довжина кола колеса.

Автором наведені результати математичного моделювання процесу різання спеціальною фасонною фрезою зношеного шару матеріалу, з термомеханічними дефектами, профілю робочої поверхні колісної пари під час відновлення на колесофрезерному верстаті КЖ20. 
Висновки та перспективи подальших досліджень. Розроблено математичну модель процесу фрезерування робочих поверхонь колісних пар локомотивів на верстаті КЖ20, за допомогою якої можна визначати зони стійких параметрів динаміки процесу фрезерування, в умовах одночасної наявності двох нежорстких елементів (оброблюваної деталі і спеціальної фасонної фрези). Використання рузультатів експериментів та математичної моделі, які були отримані автором, дозволить підвищити ефективність відновлення колісних пар фрезеруванням робочих поверхонь на верстатах КЖ20.

Використання запропонованих моделей є предметом подальших досліджень автора.

\section{Список використаної літератури:}

1. Кульбовський I.I. Аналіз впливу змін умов експлуатації взаємодіючої пари рейка-колесо на знос поверхні кочення у проектах залізничного транспорту / I.I. Кульбовський, В.О. Демченко // Автомобільні дороги і дорожнє будівництво. - 2015. - Вип. 93. - С. 192-205.

2. Колеса суцільнокатані. Технічні умови : ДСТУ ГОСТ 10791-2016 ; Чинний від 2016.09.01. - М. : Стандартинформ, 2011. - 17 с

3. Надежность железнодорожных колес, изготовленных разными способами производства / А.И. Бабаченко и др. // Металл и литье Украины. - 2019. - № 3-4 (310-311). - С. 48-57.

4. Бандажи черновые для колес подвижного состава железных дорог широкой колеи и метрополитена. Типы и размеры : ДСТУ 3717-98. - Киев : Госстандарт Украины, 1998. - 13 с.

5. Дьомін Р.Ю. Дослідження втомного руйнування бандажів коліс тягового рухомого складу / Р.Ю. Дьомін // Вісник НТУ «ХПІ». - 2017. - № 20 (1242). - С. 77-83.

6. Інструкція з формування, ремонту та утримання колісних пар тягового рухомого складу залізниць України колії 1520 мм. ВНД 32.0.07.001-2001 : Затверджено Наказом Укрзалізниці від 29.05.2001 № 305-Ц зі змінами та доповненнями затвердженими наказами Укрзалізниці від 16.11.2004 № 863-ЦЭ, від 18.12.2007 № 598-Ц та від 20.04.2010 № 046-ЦЗ / Мінтранс України. Укрзалізниця. Гол. локомотив. госп. - Київ, 2004.

7. Мутафян Л.А. Явление удара при прерывистом резании и его влияние на характер протекания износа инструмента / Л.А. Мутафян // Известия ТулГУ. Серия : Технические науки. - 2015. - Вып. 5. - Ч. 2. - С. $73-78$.

8. Станок колесофрезерный специальный модель КЖ20ТФ1 : Руководство по эксплуатации КЖ20ТФ1 000000 РЭ2, 1989.

9. Оптимизация технологического процесса ремонта колесных пар / К.В. Аверков, Т.Г. Бунькова, М.И. Бисерикан, С.В. Петроченко // Омский научный весник. - 2018. - № 1 (157). - С. 19-22.

10. Логминов В.А. Моделирование колебаний нежестких деталей при концевом фрезеровании / В.А. Логоминов, О.Л. Лукьяненко // Вісник СумДУ. Серія : Технічні науки. - 2011. - № 4. - С. 145-157.

11. Stadkowski A. Increasing the resource of milling cutters used to process the locomotive wheelsets. Part 1: Determination of cutting forces / A.Stadkowski, Yu.Proydak, V.Ruban // Transport Problems. - 2018. - Vol. 13. № 3. - P. 119-130.

12. Stadkowski A. Підвищення ефективності використання ріжучих елементів спеціальних фасонних фрез до верстатів КЖ20 / A.Stadkowski, B.M. Рубан // Технічна інженерія. - Житомир : Житомирська політехніка. № 1 (85). - C. 71-80.

13. Внуков Ю.Н. Эволюция развития исследований сил при цилиндрическом фрезеровании от статических к динамическим условиям обработки. Ч. 2 // Ю.Н. Внуков, С.И. Дядя, Е.Б. Козлова // Сучасні технології в машинобудуванні. - 2016. - № 11. - С. 20-41.

14. Ермолаев А.И. Анализ вибраций, возникающих в процессе фрезерования / А.И. Ермолаев, В.И. Ерофеев, A.С. Плехов // Вестник научно-технического развития. - 2019. - № 3 (139). - С. 12-23.

15. Зелинский C.A. Математическая модель процесса контурного фрезерования нежестких деталей / С.A. Зелинский, Ю.А. Морозов, Ю.А. Серебрий // Праці Одеського політехнічного університету. - 2015. - Вип. 1. - С. $28-33$.

16. Усольцев А.А. Общая электротехника : учеб. пособ. / А.А. Усольщев. - СПб. : СПбГУ ИТМО, 2009. - 301 с.

17. Кірієнко O.A. Теорія механізмів і машин. Деталі машин: розрахунки механічних передач / O.A. Кірієнко, Ю.М. Гузенко. - К. : НТУУ «КПІ», 2016. - 188 с.

\section{References:}

1. Kul'bovs'kyj, I.I. and Demchenko, V.O. (2015), «Analiz vplyvu zmin umov ekspluatacii' vzajemodijuchoi' pary rejka-koleso na znos poverhni kochennja v proektah zaliznychnogo transportu», Avtomobil'ni dorogy i dorozhne budivnyctvo, Issue 93, pp. 192-205.

2. Standartynform (2011), DSTU GOST 10791-2016 Kolesa sucil'nokatani. Tehnichni umovy, Chynnyj vid 2016.09.01., Moskva, 17 p.

3. Babachenko, A.I. et al. (2019), «Nadezhnost' zheleznodorozhnykh koles, izgotovlennykh raznymi sposobami proizvodstva», Metall i lit'e Ukrainy, No. 3-4 (310-311), pp. 48-57.

4. Gosstandart Ukrainy (1998), DSTU 3717-98 Bandazhi chernovye dlya koles podvizhnogo sostava zheleznykh dorog shirokoi kolei i metropolitena. Tipy i razmery, Kiev, 13 p.

5. D'omin, R.Ju. (2017), «Doslidzhennja vtomnogo rujnuvannja bandazhiv kolis tjagovogo ruhomogo skladu», Visnyk $N T U$ «HPI», No. 20 (1242), pp. 77-83.

6. Mintrans Ukrai'ny. Ukrzaliznycja (2004), Instrukcija z formuvannja, remontu ta utrymannja kolisnyh par tjagovogo ruhomogo skladu zaliznyc' Ukrai'ny kolii' 1520 mm. VND 32.0.07.001-2001, Zatverdzheno Nakazom Ukrzaliznyci vid 29.05.2001 No. 305-C zi zminamy ta dopovnennjamy zatverdzhenymy nakazamy Ukrzaliznyci vid 16.11.2004 No. 863-CE, vid 18.12.2007 No. 598-C ta vid 20.04.2010 No. 046-CZ, Gol. lokomotyv. Gosp., Kyi'v. 
7. Mutafyan, L.A. (2015), «Yavlenie udara pri preryvistom rezanii i ego vliyanie na kharakter protekaniya iznosa instrumenta», Izvestiya TulGU, Seriya Tekhnicheskie nauki, Issue 5, Part 2, pp. 73-78.

8. Stanok kolesofrezernyi spetsial'nyi model' KZh20TF1 (1989), Rukovodstvo po ekspluatatsii KZh20TF1 000000 RE2.

9. Averkov, K.V., Bun'kova, T.G., Biserikan, M.I. and Petrochenko, S.V. (2018), «Optimizatsiya tekhnologicheskogo protsessa remonta kolesnykh par», Omskij nauchnyi vesnik, No. 1 (157), pp. 19-22.

10. Logminov, V.A. and Luk'yanenko, O.L. (2011), «Modelirovanie kolebanii nezhestkikh detalei pri kontsevom frezerovanii», Visnyk SumDU, Serija Tehnichni nauky, No. 4, pp. 145-157.

11. Sładkowski, A., Proydak, Yu. and Ruban, V. (2018), «Increasing the resource of milling cutters used to process the locomotive wheelsets. Part 1: Determination of cutting forces», Transport Problems, Vol. 13, No. 3, pp. 119-130.

12. Sładkowski, A. and Ruban, V.M. «Pidvyshhennja efektyvnosti vykorystannja rizhuchyh elementiv special'nyh fasonnyh frez do verstativ KZh20», Tehnichna inzhenerija, Zhytomyrs'ka politehnika, Zhytomyr, No. 1 (85), pp. $71-80$.

13. Vnukov, Yu.N., Dyadya, S.I. and Kozlova, E.B. (2016), «Evolyutsiya razvitiya issledovanii sil pri tsilindricheskom frezerovanii ot staticheskikh $\mathrm{k}$ dinamicheskim usloviyam obrabotki. Ch. 2», Suchasni tehnologii' $v$ mashynobuduvanni, No. 11, pp. 20-41.

14. Ermolaev, A.I., Erofeev, V.I. and Plekhov, A.S. (2019), «Analiz vibratsii, voznikayushchikh v protsesse frezerovaniya», Vestnik nauchno-tekhnicheskogo razvitiya, No. 3 (139), pp. 12-23.

15. Zelinskii, S.A., Morozov, Yu.A. and Serebrii, Yu.A. (2015), «Matematicheskaya model' protsessa konturnogo frezerovaniya nezhestkikh detalei», Praci Odes'kogo politehnichnogo universytetu, Issue 1, pp. 28-33.

16. Usol'tsev, A.A. (2009), Obshchaya elektrotekhnika, ucheb. posob., SPbGU ITMO, SPb., 301 p.

17. Kirijenko, O.A. and Guzenko, Ju.M. (2016), Teorija mehanizmiv i mashyn. Detali mashyn: rozrahunky mehanichny peredach, NTUU «KPI», Kyiv, 188 p.

Рубан Владислав Миколайович - старший викладач кафедри прикладної механіки Національної металургійної академії України.

Наукові інтереси:

- $\quad$ колесофрезерна обробка робочої поверхні колісних пар на верстатах КЖ20.

E-mail: VladislavRuban@ua.fm.

Стаття надійшла до редакції 02.07.2020. 